\title{
Guest-editorial
}

\section{Logistics, Quality, and Technology Management}

\author{
An ESPRIT/COPERNICUS Symposium organised in Budapest, 9-10 December, 1996
}

The opening of national economies to world market forces has been a catalyst for restructuring the introduction of new technologies, and rapidly changing consumer markets. Increasingly, companies are reorganising design and production along broader geographical lines to optimise the effective use of skilled labour, technology, and access to markets. This has resulted in the emergence of global production networks that stimulate the growth of the most effective firms and the emergence of new industries.

The material content of products now accounts for less of total value, while knowledge content continues to increase rapidly. The fundamental global shift from material to knowledge-based comparative advantage means that nowadays natural assets do less to shape a region's economic performance than do purposefullydeveloped resources such as skills, well trained people, useable technology, available financial capital and advanced Information and Communication Technologies (ICT) infrastructure.

Together, these changes are putting pressure on manufacturing R\&D, design, component production, assembly, distribution and marketing, to allow manufacturers to utilise just-in-time supply links and anticipate demand fluctuation and distribution of goods. This creates concentration of competing, complementary and interdependent firms across several industries, including component suppliers, service providers, and final product manufacturers.

Given these developments, the following four factors now constitute the basis for a competitive business sector [1]:

- A strong economic infrastructure provides the foundation for industry to grow and adapt over time as the global economic environment changes.

- The relationships and close co-operation between firms through communication, partnerships and alliances are crucial in stimulating competition and boosting efficiency and innovation.

- To meet changing market conditions, many companies have restructured their internal organisation and introduced flatter, decentralised structures, with continuous improvement, knowledgebased IT systems and quality management. New working practices implemented include greater use of flexible working conditions, increased training and responsibility devolved upon all layers of personnel.

- While managing an efficient and competitive supply network creates the potential for high performance, business as a whole must be customer focused, picking up on the trends in global demand, to ensure maximum performance by targeting promising growth sectors.

\section{The role of ICT in manufacturing}

Companies world-wide face a revolution in product and process technologies. ICT, for example, offer companies new ways to satisfy customers and change the way goods are produced and services delivered. Innovative companies are exploiting new forms of work organisation to set new levels of cost, quality and customer responsiveness, many of which having direct implication on overall industry structure and changing the links and organisation of relationships between companies.

The manufacturing sectors are impacted by the development of ICT in several ways. Technological developments support, for example, rapid development of high quality products tailored to market requirements, the time reduction of the product design process and the concurrent engineering practices. ICT applications enable small and large organisations to 
be linked to easy access, cost-effective networks providing information, products and services in production activities, to look for new business and market opportunities, etc.

Within this context, the European Union's Information Technologies (IT) Programme is a multi-sectoral cross-disciplinary industrial oriented RTD Programme in underpinning the competitiveness of the whole European economic fabric [2]. The programme contributes to the creation of advanced skills base and helps to pave the way for Europe's advent into the Information Society.

In the face of quite remarkable technological developments and economic opportunities, leading global industrial players are reassessing strategies and options. Large and small companies and professional users are already leading the way in exploiting the new technologies to raise the efficiency of their management and production systems. And more radical changes to business organisation and methods are on the way.

The CEECs economies and new possibilities for participation under the IT Programme Research Actions

Until 1989, the lack of internationalisation of the industry of Central and Eastern European Countries (CEECs) and the fact that CEEC industry's production patterns were decided by planning authorities and not by the market, led to a decoupling of its technological progress and associated structural changes from those in West Europe. Since 1989, as the CEEC economies integrate in the wider European economy, the transition to become market economies generates particular needs for adjustment and a number of structural changes become of significant importance.

In the beginning of 1996 and in the context of accelerating the transition phase of the CEECs economies and further supporting their research organisations and industry to gain experience in working with their Western European counterparts, it has been decided to open the EU IT Programme for participation from CEECs.

\section{The 1st ESPRIT-COPERNICUS Symposium in the area of IT and manufacturing}

Within the international framework described above and with the objectives to disseminate emerging re- sults of funded COPERNICUS and ESPRIT projects in the "IT and manufacturing" area and to provide information on co-operation possibilities in Research and Technological Development, the European Commission, in collaboration with MTA/SZTAKI - Hungary, has organised a Symposium in Budapest entitled "The ESPRIT/COPERNICUS Symposium on Quality, Logistics and Technology Management - Use and Benefits of IT in Manufacturing". The Symposium was held on 9-10 December 1996 in Budapest and has been equally supported by OMFB - the National Committee for Technological Development of Hungary.

\section{The Symposium's topics}

The Symposium comprised three main themes, i.e., Logistics, Quality and Technology Management. All three themes concentrated in the use and benefits of IT in Manufacturing.

\section{Logistics and relating IT tools for manufacturing}

In several industrial sectors, production is increasingly spread out geographically and across companies through networks of alliances and global partnerships. As companies concentrate on their core activities, the trend is also towards increased subcontracting and outsourcing of non-core activities such as design of product development, component manufacturing or services.

The need to share information and collaborate at all phases of the business cycle, across the production network and across national and international boundaries has particular consequences for all types of manufacturing companies and especially for SMEs. The key is to reduce costs as well as to gain access to existing or new market distribution networks.

Within this framework, improved logistics operations for efficient planning and control of manufacturing and supply networks and for optimisation of the underlying transportation costs of goods are considered of critical importance for companies in order to ensure a high productive flow and satisfy the customer expectations by providing just-in-time delivery. The economic importance of logistics in modern economies is reflected by the following figures: logistics costs represent, respectively $6.7 \%, 7.8 \%, 8.7 \%$ and $12.1 \%$ of companies' sales revenue in The Nether- 
lands, UK, France and Germany (Source: PE International, 1991).

ICT tools provide means for better planning, monitoring and controlling manufacturing processes, machines and personnel, for planning and controlling transport and delivery of goods, for modelling and simulating the activities of the supply chain hence enabling intelligent decision making and shortening the time for action and reaction to events, for rapid communication of orders, data and bills, etc.

At the Symposium, presentations on logistics issues highlighted several logistics elements that characterise successful companies, reported several experiences gained when operating logistics systems in supply chains and described issues that still have to be addressed for improving logistics operations in the coming years. Given that the awareness of CEECs industry to logistics issues is currently rather low, these presentations enabled Eastern participants to understand the importance of logistics in current business practices. Logistics will certainly receive increasing attention in the nearby future in CEECs and the Symposium served as an excellent dissemination platform for logistics issues and related IT tools.

\section{The importance of Quality related IT tools in manufacturing}

Changing market requirements and hard and unremitting competition are critical issues for enterprises which cause them to be in upheaval and continuously seeking for appropriate methods and means. Quality is attracting significant attention since primarily dealing with satisfaction of customer requirements. Offering better services, better customer orientation, guaranteeing quality in design and production of goods and reliable delivery times by respecting emergent environmental quality standards have become strategic key issues for companies for improving and maintaining their competitive advantage internationally.

Efficiency and competitiveness of supply networks for manufacturing critically depends on quality in relations and quality in design and manufacturing of products and provision of services between a company and its suppliers and subcontractors: suppliers' and sub-contractors' quality is decisive since weaknesses in one of the links in the production and marketing chain can constitute a significant handicap for the entire network.
The role of ICT has been crucial in the development of quality approaches and methods since providing means for systematising, documenting, analysing and supporting business processes; examples include rapid collection, interpretation, analysis and control of large data collections for entire manufacturing processes and products and their fast and reliable communication over the whole supply chain, modelling, simulation and decision making methods and tools enabling continuous product and process improvement, closer interlinking between quality experts in the supply chain, etc.

At the Symposium, presentations on quality issues reported on specific experiences and on various initiatives on quality support and on standardisation/certification efforts both on EU and the CEECs. They emphasised the importance of quality and IT as well as the role of standards as driving factors for improving quality in manufacturing. Discussions following these presentations enabled the establishment of some useful conclusions in the quality field such as the following:

- The interest of CEECs industry to TQM seems to be high but the development road will be long. Eastern Europe needs more focused tools on quality management than the ones actually offered by the EU industry.

- Despite the fact that many RTD projects on quality have been undertaken so far, the penetration of their results in the market and especially in SMEs is still low. Future actions in the field should focus on a wider dissemination of achieved results in quality, specialised training and education actions as well as on efforts for providing IT quality tools which are cost-effective and easily customisable to meet successfully the individual company's requirements.

Finally the issue of quality in other areas than manufacturing and in particular in the service sectors and in the material field has also been raised.

\section{Technology Management}

In a knowledge-based society, the management of technological assets is a main element in competition - issues such as getting access to technology, people and markets are of paramount importance. The cost of developing and introducing new technology is increasing and in a fast changing world the time it takes for technology becomes obsolete very rapidly. 
Novel technology and innovations have a profound impact on the individual worker and the organisation as a whole. Emphasis nowadays is to make knowledge available/useable and in this systematisation plays a key role.

In order to manage technology, organisations have to decide on a variety of issues such as:

- Make or buy?

- Whether and how to protect Intellectual Property.

- In which domains to cooperate and in which to compete.

- What is the best route to exploitation.

- How to identify and nurture promising concepts and innovations.

- How to value intangible assets.

The above topics were presented under the heading Technology Management. Experience resulting from real collaborations mainly in the domain of Research or Development was presented.

\section{Conclusions}

The Symposium was targeted at industrialists, researchers, representatives of industrial associations, and regional and national authorities from Eastern and Western Europe. It provided an open forum to discuss and learn about latest developments and trends in Logistics, Quality and Technology Management. Emphasis was given on exchanging practical experience in the deployment of IT solutions.

Several of the Symposium participants highlighted the importance of such events for CEECs and especially for the hosting country as a platform for strengthening European collaboration in the industrial sector. In general, the Symposium has served as a good platform for establishing new partnerships and networks for forming new Consortia to tackle the new challenges and to transfer the knowledge from EU industry to the CEECs.

\section{Thomas Skordas and Willy Van Puymbroeck}

European Commission, Brussels, Belgium

\section{References}

[1] European Commission, Panorama of EU Industry 97, Office for Official Publications of the European Communities, 1997.

[2] European Commission, ESPRIT Review Board 1996 Report Making Progress Happen through Development, Application and Diffusion of Information Technologies, Office for Official Publications of the European Communities, 1997. 